\title{
Reformation On The Control Mechanism On Safety In China
}

\author{
Yu-Hui Li,You-Fen Zhang, Bo Li, Kai-Xiong Liu \\ Faculty of Information Engineering and Automation, Kunming University of Science and Technology, Kunming, China \\ E-mail: 1484946977@qq.com, 1242763560@qq.com, lbly9177@163.com,1057716441@qq.com
}

\begin{abstract}
At present, there are many problems in the regulation mode of food safety supervision. This paper deep analyze on the current food safety supervision, create a new food safety regulatory system model. Therefore it can provide reference model on the research on the supervision of food safety in our country further study and innovation.
\end{abstract}

Keywords-supervision system model; improvement measures; food safety; management and control

\section{INTRODUCTION}

Food safety is closely related to the vital interests and welfare of consumers, and food safety and supervision have been widely concerned by all sectors of society. China's food safety system has been the introduction of multi sectoral supervision mode, in 2009 through the "food safety law" still continues to follow the model of subsection [1]. This supervision system has three major problems: the first is that the administrative law system is not perfect, and the supervision of the main responsibility, authority are by a large numbers of administrative normative documents which is lower level; the second is regulatory authorities, resulting in the regulatory vacuum and overlap; the third is the regulatory body rights and responsibilities are unequal, so dereliction of duty and supervision of the phenomenon is widespread in the process of supervision. These are the reasons for the frequent problems of food safety in our country. So it is very necessary and urgent to analyze the food safety supervision system and put forward effective supervision model and related measures.

\section{THE MAIN BODY OF FOOD SAFETY SUPERVISION SYSTEM IN CHINA}

The regulatory body of the food safety supervision system in China is based on a government entity of regulators, and establishes and improves relevant laws and regulations. Industry organization and management strength, producers and consumers participate in the way of combining to form stratified supervision system of multi subject. The implementation of government led and non-governmental organizations involved in a wide range of food safety supervision and supervision of multiple main modes can ensure the effective supervision of major food safety issues [2]. Food safety supervision and authority of the main body, is shown in Fig. 1 .

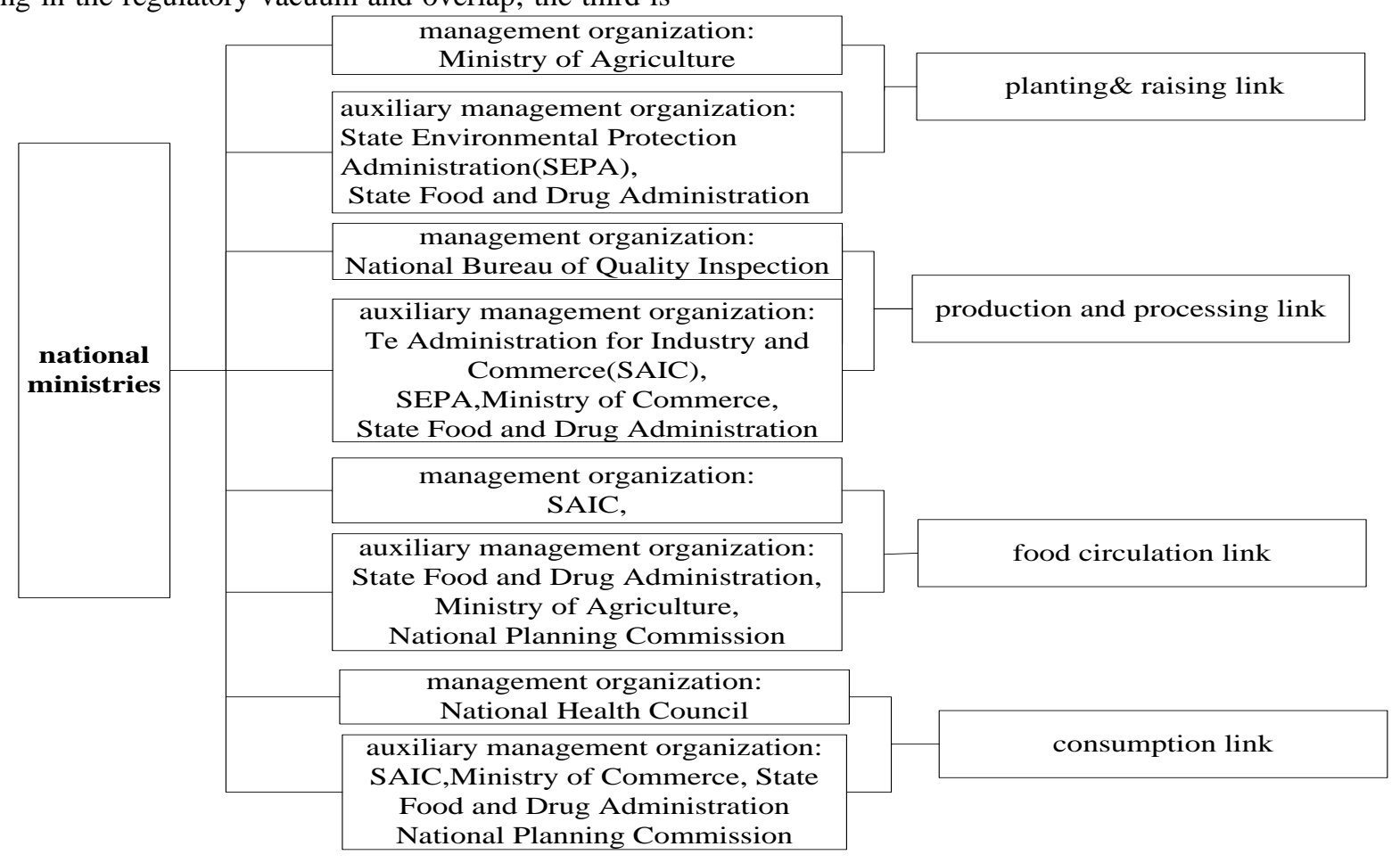

Figure 1. The subject and authority of food safety supervision in China. 


\section{CREATE A NEW FOOD SAFETY SUPERVISION SYSTEM MOSEL}

In order to protect the people's health and life safety, to further strengthen food safety supervision, improve the national food safety regulatory system, a new model of food safety regulatory system, combined with the information engineering supervision model, is established, as shown in Fig.2.

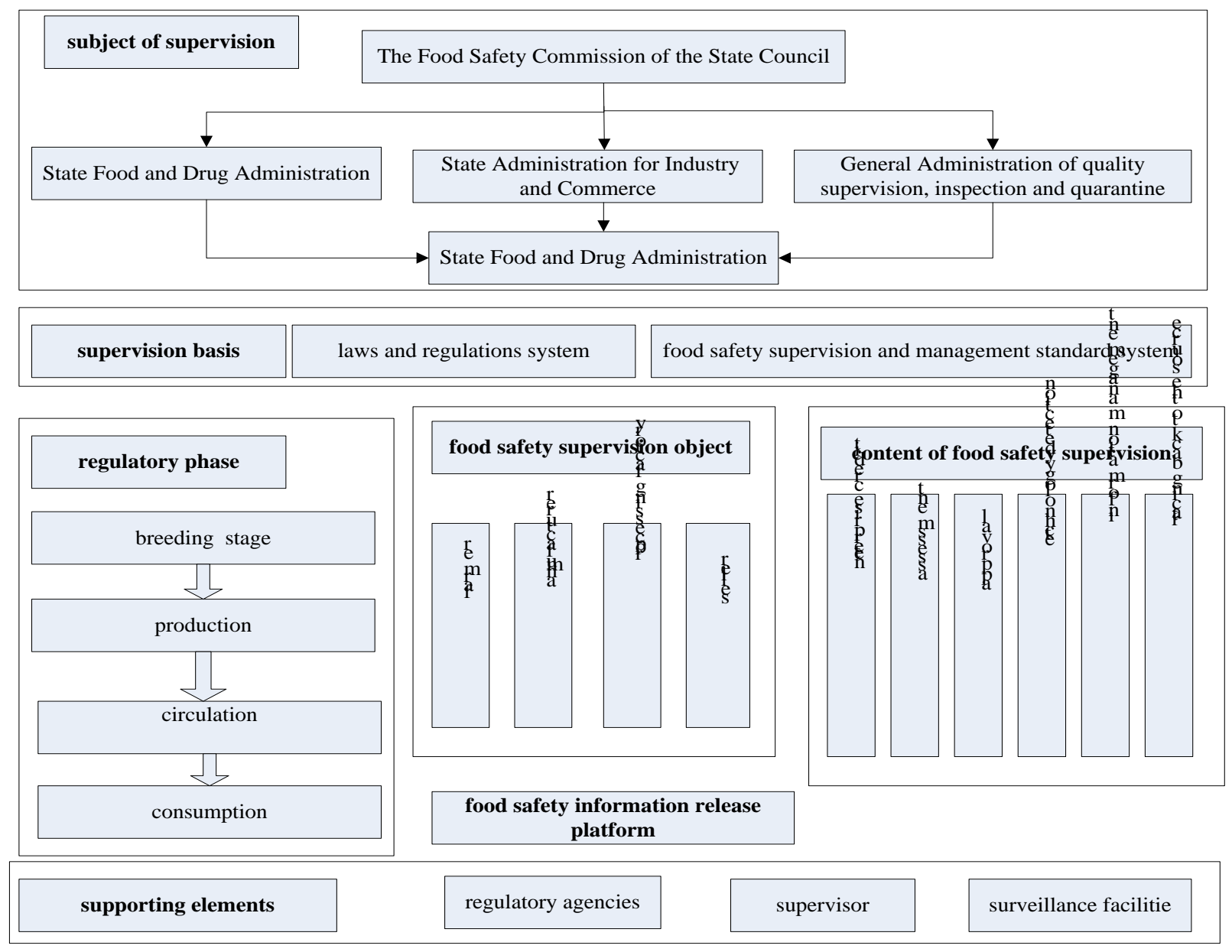

Figure 2. A new model of food safety supervision system.

New food safety regulatory system model mainly consists of 6 parts: one is the regulatory body, including food safety committee of the State Council, food and drug supervision and Management Bureau, industrial and commercial administrative bureau, quality supervision, inspection and quarantine. Two is the basis of supervision, that is, the regulatory system, including regulatory laws and regulations system and standard system. Three is the regulatory stage, which is, production, processing, transportation, sales stage. Four is the regulatory object, including inputs, agricultural production, agricultural products processing, food processing, retail, etc. Five is regulatory content, including corporate credit, certification and other aspects of the recognition. Six is the support of the regulatory elements, including regulators, personnel, facilities, etc. Correspondingly, 3 systems and 1 environmental condition are necessary, including food safety regulatory process system, system and implementation of the system, information systems and environmental conditions. The government, the market, the third sector and society, "four in one" food safety regulatory model is initial formed.

\section{MEASURES TO IMPROVE CHINA'S FOOD SAFETY MANAGEMENT AND CONTROL MECHANISM}

Improvement of comprehensive food safety control mechanism need to clear the food safety committee as a rigid administrative body, adopt the gradual mode of administrative supervision, be based on the supervision legal system of the administrative main body organization. Encourage the participation of the people, so improve the responsibility mechanism.

\section{A. Regard the Food Safety Committee as Rigid Administrative Body}

From the advanced experience from abroad, improving 
food safety committee's role is to improve food safety issues key move. To improve the food safety committee, it is necessary to make it clear that it is a rigid administrative body [3].

First, clarify the responsibilities of the food safety committee. The food safety committee is determined as an administrative subject of administrative authority. In the "food safety law", the implementation details must be clearly which defined the Food Safety Commission's terms of reference. Food safety committee as the highest unified coordination agencies, direct supervision and management of the various regulatory authorities. Second, improve the status of the food safety committee. Food safety committee, as a high-level coordinating body, whose position must be independent, must have real power is a permanent body, under the direct leadership of the premier of the State Council, and whose level slightly higher than other regulatory authorities.

\section{B. Improve the Regulatory Body of the Legal System}

Administrative Organization Act is the legal basis of the regulatory body existence and operation .To establish a comprehensive food safety control mechanism, there must be a corresponding regulatory body of administrative organization law systems [4] .In the reform and exploration of the food control mechanism, in addition to the "food safety law", and the rest set and distribute the administrative powers of the regulatory body with a large number of regulatory documents. At present our country administrative organization law system is not perfect, the standard document has certain positive significance to the regulation subject's stipulation. But in the long run, it is necessary to strictly control the documents' substantive legislative power after gradually improving the food safety regulatory bodies of administrative organization law system and establish the review mechanism of normative documents. It is determined not to replace the legal practice with general normative documents when it comes to related to the organization law.

\section{Adopt Gradual Classification and Unified Administrative Supervision Mode}

The essence of the regulatory model is the distribution of regulatory power [5].Food safety, from farm to table, is multidisciplinary extremely complex problem. Administrative system of our country at present is not even a department can manage the problem. The overall idea of China's food safety regulatory system: in the near future, multi sectoral system turn into a comprehensive department system, and a single department centralized supervise certain categories of food, and ultimately a single department of all food unified supervise. Accelerating the reform of the system at the present stage should gradually designated the production link supervision, which is still belongs to the quality inspection and the Department of agriculture, and the circulation link supervision , still belongs to Industry and Commerce ,as the national food and drug supervision and Management Bureau. It can realize the regulatory system and functions of the transition according to the actual situation.

\section{Strengthen Administrative Accountability on Supervision of Dereliction of Duty and Establish A Consistent Responsibility System of Accountability}

Administrative accountability system is the basic requirement of modern society to the government, but also an urgent need for the government itself, the government not only to build into a limited government, efficient government, government service, also be a responsibility of the government [6]. In China's food supervision, lack of supervision and regulatory omission phenomenon is still widespread. The phenomenon is a "lazy government". Regulatory authorities in the situation "lazy government" are very likely to cause food safety incidents. Therefore, strengthen the supervision of dereliction of duty administrative accountability system is particularly critical. Accountability system, including administrative responsibility and judicial responsibilities. Administrative responsibility, in theory, is divided into two kinds in the food safety supervision: Legal responsibility of the supervisory organization and legal liability of the public servants.

Strengthen government regulatory responsibility of government. The regulators accountability can't be confined to internal disciplinary action, but to truly implement legal liability. Therefore, it is necessary to establish framework of the system, in which judicial accountability, authority and the administrative authorities investigated, supplemented by the illegal acts of regulatory responsibility investigation system, namely, litigation system, administrative reconsideration system and power of the people's Congress supervision system integration.

\section{E. Establish Information Platform to Encourage the Participation of the People}

China's food quality and safety supervision is executed by different administrative departments. Such rights separate and alone for the government's regulatory system cause the government lack of analysis of accident data and limited information can be shared under the current management system, which greatly reduces the analysis efficiency of food quality and safety incidents. At present, at all levels of government, the release mechanism of food safety risks is not perfect, the majority of consumers do not timely and full understand that food safety risk exists. Therefore, food safety supervision departments at all levels should establish and improve the food information release platform and mechanisms to protect the public's right to information [7].

\section{SUMMARY}

Based on the food safety basic and applied research, this paper analyze food safety supervision system, create new regulatory system model on the China's food safety control mechanisms, and for China's food safety control mechanisms currently propose food safety Commission rigid administrative body and take progressive classification unified administrative supervision mode control strategy on the basis of the legal system. 


\section{ACKNOWLEDGMENT}

This research was financially supported by the Provincial key projects (research on the mechanism of food safety conditions and the construction of the platform 2013SZ)and National Natural Science Foundation of China( Research on the key technologies of the spatial temporal correlation of motion vehicle in Distributed Video(61363043)).

\section{REFFERENCES}

[1] Xiaojun Liu. Research of government control of food safety [J] Political Science and Law, 2010: 42.

[2] Nannan Li. Study of food safety supervision mode, [J] Peking
University, 2010: 15.

[3] Tingting Zhang. Chinese food safety regulation reform research [M] Beijing: China Logistics Publishing House, 2010: 21.

[4] yingJuan Ma. Regulatory and economic incentives: the new issues of China Administrative Law, Journal of the Graduate School of Chinese Academy of Social, 2007:2.

[5] Hanhua Zhou. institutional reform and legal construction --- different views on "most of the system" , "Economic Observer reported", 2003-03-03.

[6] Yu Jiu. administrative accountability, "Public Administration \& Law” 20067.

[7] Yiping Long, Hongwei Xu. Food Safety and Government Regulation [J] Hubei University of Economics, 2006, 12: 93-94,146. 